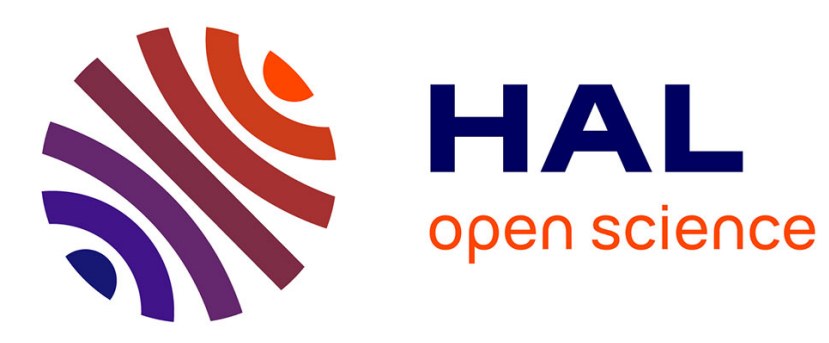

\title{
Organismes filamenteux de l'ambre du Santonien de Belcodène (Bouches-du-Rhône, France)
}

Simona Saint Martin, Jean-Paul Saint Martin, Vincent Girard, Didier

Néraudeau

\section{- To cite this version:}

Simona Saint Martin, Jean-Paul Saint Martin, Vincent Girard, Didier Néraudeau. Organismes filamenteux de l'ambre du Santonien de Belcodène (Bouches-du-Rhône, France). Annales de Paléontologie, 2013, 99 (4), pp.339-360. 10.1016/j.annpal.2013.03.001 . insu-00934868

\section{HAL Id: insu-00934868 \\ https://hal-insu.archives-ouvertes.fr/insu-00934868}

Submitted on 22 Jan 2014

HAL is a multi-disciplinary open access archive for the deposit and dissemination of scientific research documents, whether they are published or not. The documents may come from teaching and research institutions in France or abroad, or from public or private research centers.
L'archive ouverte pluridisciplinaire $\mathbf{H A L}$, est destinée au dépôt et à la diffusion de documents scientifiques de niveau recherche, publiés ou non, émanant des établissements d'enseignement et de recherche français ou étrangers, des laboratoires publics ou privés. 


\section{Organismes filamenteux de l'ambre du Santonien de Belcodène (Bouches-du-Rhône,}

France)

Simona Saint Martin ${ }^{\mathrm{a}}$, Jean-Paul Saint Martin ${ }^{\mathrm{a}}$, Vincent Girard ${ }^{\mathrm{b}, \mathrm{c}}$, Didier Néraudeau ${ }^{\mathrm{d}}$

${ }^{\text {a }}$ UMR CNRS 7207 CR2P, Muséum National d'Histoire Naturelle, Département Histoire de la Terre, 8 rue Buffon, 75005 Paris, France

${ }^{\mathrm{b}}$ Centre de Bio-Archéologie et d'Ecologie (UMR 5059 CNRS/Université Montpellier 2/EPHE/INRAP), Institut de Botanique, 163 Rue Auguste Broussonet, 34090 Montpellier, France

${ }^{c}$ Université Montpellier 2, Place Eugène Bataillon, 34095 Montpellier, France

${ }^{\mathrm{d}}$ UMR CNRS 6118, Université Rennes 1, Campus de Beaulieu, 263 avenue du Général Leclerc, 35042 Rennes, France

\section{Corresponding author: Saint Martin Simona}

Muséum National d'Histoire Naturelle, Département Histoire de la Terre, 8 rue Buffon, 75005 Paris, France

E mail: simsmart@mnhn.fr

Telephone: (33) 0140793021

Fax: (33) 0140793580

\section{Résumé}

Des grains millimétriques d'ambre sont associés à des débris ligniteux dans la série marine du Santonien de Belcodène (Bouches du Rhône, France). Il s'agit surtout de grains en forme de goutte, jaunes à rougeâtres, plus ou moins transparents. Ils révèlent la présence de divers micro-organismes appartenant à des procaryotes (bactéries, actinomycètes) ou des eucaryotes (champignons) décrits ici pour la première fois. Ces microorganismes constituent parfois des croûtes à la périphérie des grains d'ambre et se sont développés de manière centripète dans la résine encore fluide. Le milieu de dépôt de l'ambre était ouvert sur des influences marines, tandis que le milieu de formation des coulées de résine était une forêt côtière constituée essentiellement d'angiospermes.

Mots-clés : Bactéries, Champignons, Micro-organismes, Ambre, Santonien, SE France 


\begin{abstract}
Millimetric amber grains associated with lignite debris were recently reported in the Santonian marine series from Belcodène (Bouches du Rhône, France). These are mainly yellow to reddish drop shaped grains, more or less transparent. They reveal the presence of various microorganisms, belonging to prokaryotes (bacteria, actinomycetes) and eukaryotes (filamentous fungi) here described for the first time. These microorganisms form sometimes crusts around the amber grains and grew centripetally into the ancient resin before its solidification. The depositional environment of amber was open to marine influences, while the original environment of resin flow was a coastal forest with dominant angiosperms.
\end{abstract}

Keywords: Bacteria, Fungi, Microorganisms, Amber, Santonian, SE France

\title{
1. Introduction
}

L'ambre est un matériau fossile particulier qui a permis la préservation d'organismes parfois peu ou mal représentés dans le registre fossile (e.g. amibes, bactéries, champignons). Si les macro-inclusions, notamment les insectes, ont fait l'objet de très nombreux travaux, les micro-organismes de l'ambre ont par contre été seulement plus tardivement étudiés en détail (Girard, 2010). Les problèmes liés aux techniques et méthodes d'observation et les difficultés d'identification par des caractères morphologiques relativement simples en sont probablement les causes (Martín-Gonzáles et al., 2008; Girard, 2010). Des micro-organismes (procaryotes ou eucaryotes) préservés dans l'ambre sont connus du Carbonifère au Récent dans de nombreux gisements à travers le monde (voir listes dans Girard, 2010 ; Saint Martin et al., 2012). Ces dernières années, l'étude de plusieurs gisements crétacés français a apporté de nouvelles informations sur le monde des micro-organismes mésozoïques et les différentes conditions de formation des gisements (Breton et Tostain, 2005 ; Girard et al., 2008 ; Girard, 2009 ; Girard et al., 2009a,c,d).

En Provence, plusieurs sites ambrifères d'âges cénomanien à santonien (Crétacé supérieur) ont été recensés (Nel et al., 2004 ; Perrichot et al., 2007 ; Onoratini et al., 2009a ; Ragazzi et al., 2009), mais peu de travaux paléontologiques leur ont été consacrés. Plus localement, dans les Bouches du Rhône, la présence à Martigues de "succinite" est connue depuis le 19ème siècle (Vasseur, 1894). Redécouvert il y a peu de temps (Guiliano et al., 2006 ; Onoratini et al., 2009a), cet ambre a livré un assemblage diversifié de micro-organismes incluant des procaryotes (bactéries, actinomycètes) et des champignons filamenteux (Saint Martin et al., 
2012). D'autres sites des Bouches-du-Rhône renferment également de l'ambre, mais n'ont pas encore été étudiés dans le détail. C'est le cas du gisement d'Ensues, situé sur la Côte Bleue au Nord-Ouest de Marseille, et celui de Belcodène, situé au Nord de la ville d'Aubagne. Cet article concerne le gisement de Belcodène qui a fourni des échantillons d'ambre étudiés pour la première fois du point de vue micropaléontologique. Il se propose principalement de détailler les inclusions filamenteuses et de définir leur modalité de préservation et de croissance. Les données apportées sur les caractéristiques de l'ambre permettent également de mieux comprendre la structuration des forêts ambrifères du Santonien et d'analyser les principaux points qui les différencient de leurs homologues cénomaniens.

\section{Cadre géologique}

Le gisement ambrifère de Belcodène (Fig.1A) s'inscrit dans le cadre plus général d'une sédimentation à dominante marine du Crétacé supérieur, renfermant plusieurs épisodes de constructions à rudistes. Ainsi, dans le secteur de Belcodène-La Bouilladisse, le Santonien, épais d'une cinquantaine de mètres et reposant sur le Jurassique du massif de Régagnas, est surtout constitué de calcaires comprenant des intercalations marneuses et gréseuses. Collot (1890) décrit aux alentours du quartier de La Pomme (Ouest de Belcodène), dans un ravin maintenant occupé par une autoroute, une succession « sénonienne » qui comporte, au dessus d'un niveau marneux d'une dizaine de mètres d'épaisseur, des grès en plaquette avec des bois fossiles et des coquilles de rudistes (Radiolites, Hippurites) et autres bivalves (Cardium, Mytilus).. L'âge santonien de cette série est par ailleurs précisé par Philip (1974) qui propose également une coupe à la Pomme, mais un peu à l'ouest de celle livrée par Collot, ne comportant apparemment pas d'intercalations ligniteuses, mais des marnes à polypiers.

C'est le niveau gréseux ligniteux décrit par Collot (1890) qui renferme des grains d'ambre. Actuellement, ces sédiments affleurent uniquement sur le talus est de l'autoroute A52 qui relie Aubagne à Aix-en-Provence, à proximité de la commune de Belcodène. Malgré le recouvrement végétal, on peut distinguer, depuis la base visible au niveau de l'autoroute, la succession suivante (Fig. 1B,C) :

- calcaires construits à rudistes ;

- calcaire noduleux $(0,50 \mathrm{~m})$;

- marnes bleuâtres $(8-10 \mathrm{~m})$ renfermant de nombreux individus du corail solitaire Cunnolites polymorpha Goldfuss, 1826, des foraminifères, des gastéropodes...; 
- sables feuilletés indurés, riches en fossiles marins (coraux abondants, mollusques, bryozoaires, échinides...) renfermant également des restes ligniteux et des grains d'ambres $(0,4 \mathrm{~m})$

- marnes feuilletées à lignite et ambre, renfermant également des coraux solitaires de petite taille du genre Micrabacia, divers gastéropodes marins, des bryozoaires, des radioles d'échinides, des articles de crinoïdes, des foraminifères, des ostracodes...;

- grès jaunâtres $(1 \mathrm{~m})$ à empreintes de végétaux;

- calcaires à rudistes.

Si les grains d'ambre sont abondants et repérables directement sur l'affleurement dans les grès en plaquettes, ils sont déjà présents, en quantité moindre et dans les fractions plus fines du sédiment, dans les marnes à coraux.

\section{Matériel et méthodes}

Du sédiment contenant des grains d'ambre a été échantillonné à plusieurs niveaux de la couche à lignite. Pour extraire ces grains, un total de 20-30 kg de sédiment brut a été prélevé puis traité en laboratoire. Après désagrégation de l'argile dans de l'eau, et rinçage à l'eau distillée, le résidu a été tamisé avec une maille de 0,250 $\mathrm{mm}$. L'ambre a été séparé par tri manuel sous une loupe binoculaire. Au total, environ une centaine de grains a pu être extraite du sédiment.

L'étude a ensuite porté sur des lames minces pétrographiques, des sections polies et des lames d'esquilles. Les lames ont été préparées en plaçant des fines esquilles d'ambre dans du baume Eukit et protégées ensuite par une lamelle afin d'éviter une possible contamination. Lames minces et préparations d'esquilles ont été étudiées avec un microscope optique (Zeiss Axioscope 40) avec des objectifs x40, x63 et x100 à immersion. Cette méthodologie a l'avantage de bien mettre en valeur les inclusions filamenteuses de très petite taille, décrits dans le présent travail, mais s'avère moins efficace pour détecter les inclusions de microfossiles de plus grande taille (amibes testées, algues...), et a fortiori des arthropodes qui font l'objet d'autres investigations. Le microscope confocal à épiflorescence laser Leica TCS SP5 a été utilisé pour tester les phénomènes d'autofluorescence et déterminer ainsi la nature organique de certaines inclusions (Ascaso et al., 2003).

Des examens au Microscope Electronique à Balayage (MEB) ont aussi été réalisés au moyen d'un MEB XL 30 ESEM Philips. Dans ce but, des morceaux d'ambre ont été cassés et les surfaces de cassure immédiatement recouvertes d'or. Cette méthode permet d'examiner une 
surface fraîche en minimisant les risques de contamination. Pour une observation de surfaces plus anciennement exposées à l'air, il est recommandé de suivre le protocole proposé par Girard et al. (2009b) afin d'éliminer toute source de contamination.

\section{Caractéristiques de l’ambre}

Si l'on considère la morphologie et l'allure apparente des grains d'ambre prélevés dans le sédiment, deux types principaux se dégagent : les grains en forme de gouttes automorphes $(90 \%)$ et les grains noduleux irréguliers, façonnés en milieu aquatique (10\%) (Fig. 2A,3C-D). Seuls de très rares morceaux d'ambre de taille plucentimétrique translucides ont été récoltés.

Les grains d'ambre en forme de goutte ont une section circulaire ou ovoïde (Fig. 2B-G). Leur allongement varie de $0.5 \mathrm{~mm}$ à $5 \mathrm{~mm}$. Certains grains sont parfaitement translucides de couleur jaune, brune ou rouge (Fig.2 A-C). D'autres grains présentent un centre translucide et une périphérie plus ou moins marquée sombre, à la surface lisse ou craquelée (Fig. 2D,E). En section, cette zone périphérique est rouge et contraste avec le reste du grain plus translucide (Fig. 2F,G,H). Dans quelques cas, on observe aussi un cortex beige peu épais (100 $\mu \mathrm{m})$. Certains grains peuvent être partiellement ou totalement envahis de zones plus opaques, brunes à beiges (Fig. 2I). De nombreux grains sont enveloppés d'une mince croûte blanche calcitique (Fig. 2A, Fig. 3A,B) correspondant probablement à un ciment marin précoce. Cette croûte a ainsi scellé la structure des grains et leurs systèmes de craquelures superficielles.

D'autres grains, de plus grande dimension, irréguliers et asymétriques $(1-4 \mathrm{~cm})$ et globalement opaques (Fig. 3C,D) présentent le même aspect que l'ambre terreux décrit à Martigues (Guiliano et al., 2006 ; Saint Martin et al., 2012).

Des incrustations, recouvrant la mince couche calcitique quand elle existe, ou des enclaves de sédiment dans les grains d'ambre renfermant notamment des foraminifères (Fig. 3E) attestent le caractère marin du milieu de dépôt.

\section{Micro-organismes}

\subsection{Diversité des micro-inclusions}

L'ambre de Belcodène contient plusieurs types de microfossiles filamenteux. Ils correspondent tous à des filaments ramifiés, au diamètre compris entre 0,5 et $6 \mu \mathrm{m}$, identifiables comme des actinomycètes, diverses bactéries et des champignons filamenteux. 
L'identification moderne des bactéries, y compris les actinomycètes, repose sur du matériel de culture et sur des études génétiques. La taxinomie des actinomycètes actuels est aussi très dépendante des analyses chimiques de la paroi cellulaire et également des aspects morphologiques du mycélium aérien et des conidies (Holt et al., 2000). A partir du matériel fossile, ces critères sont délicats, voire impossible, à mettre en évidence en raison des difficultés d'investigation et de la préservation sélective. Selon Waggoner (1994), l'identification dans l'ambre de microfossiles assimilables à des actinomycètes avec des actinomycètes vivants basée sur des seuls paramètres morphologiques peut être tentée, mais avec beaucoup de réserves.

De plus, la discrimination entre actinomycètes et champignons filamenteux dans l'ambre est également délicate (Martín-Gonzáles et al., 2009). Poinar and Buckley (2007) ont soulevé le problème de la détermination des champignons filamenteux trouvés dans l'ambre en rapport avec les champignons filamenteux actuels, ceci en raison d'un nombre réduit de caractères visibles. Dans l'ambre de Belcodène, nous avons observé certains caractères morphologiques, comme les hyphes septés, qui nous ont permis de distinguer les champignons parmi les autres structures filamenteuses.

En raison de toutes ces difficultés, nous avons préféré adopter une approche prudente et, en conséquence, la détermination des microfossiles peut être considérée seulement comme une proposition.

\subsection{Bacteria}

\subsubsection{Actinomycètes $A$}

Ces filaments translucides de $0,5 \mu \mathrm{m}$ à $0,8 \mu \mathrm{m}$ de diamètre ont été observés uniquement dans le cortex fin beige entourant les grains d'ambre en forme de goutte. Ils présentent des ramifications dichotomiques régulières (Fig. 4A,B) selon un angle compris entre $60^{\circ}$ et $100^{\circ}$. La distance entre les ramifications est d'environ 3-6 $\mu \mathrm{m}$. La densité du réseau de filaments est plus élevée vers la périphérie et tend à diminuer vers le centre. Les terminaisons des filaments les plus éloignés de la périphérie présentent un aspect en « V » caractéristique, avec un angle de la fourche d'environ $60^{\circ}$, l'apex des rameaux étant orienté vers le centre du grain. L'organisation du réseau mycélien et le diamètre des filaments correspondent assez bien à ceux décrits chez les actinomycètes. Des filaments similaires ont été décrit à Martigues (Saint Martin et al., 2012) et dans l'ambre du Sud-Ouest de la France (actinomycètes de type A 
définis par Girard (2010)). L'absence de structures de reproduction ne permet pas une identification générique plus précise.

\subsubsection{Actinomycètes $B$}

Ces filaments s'observent sous deux types de morphologies : des filaments ramifiés indépendants et des petits amas d'environ 20-30 $\mu \mathrm{m}$ de diamètre, assez peu fréquents, dispersés dans l'ambre. Les filaments mesurent de 0,7 à $1 \mu \mathrm{m}$ de diamètre et présentent plusieurs ramifications (Fig. 4C) pouvant être issues d'un même point de croissance. Les dichotomies surviennent à une distance d'environ 3-4 $\mu \mathrm{m}$. L'angle des ramifications est souvent proche de $90^{\circ}$. Certains filaments montrent des terminaisons droites ou légèrement incurvées. Des actinomycètes similaires ont été décrits par Waggoner (1993) dans l'ambre éocène des Etats-Unis sous le nom de cf. Streptomyces et dans l'ambre santonien de Martigues (Saint Martin et al., 2012). Les exemplaires observés à Belcodène ne présentent pas de structure reproductive permettant une détermination plus précise.

\subsubsection{Actinomycètes $C$}

Il s'agit de réseaux de filaments retrouvés dans des gouttes translucides d'ambre. Le diamètre des filaments varie entre 0,5 et $1,5 \mu \mathrm{m}$. On observe des longs filaments légèrement incurvés sur lesquels se développent à angle droit des ramifications secondaires portant des ramifications tertiaires se terminant en hélice (Fig. 4 D-I). Ces hélices montrent plusieurs morphologies : hélices à tour de spire régulier (Fig. 4I), hélices à tour de spire croissant (Fig. 4F,H), hélices à tour de spire variable (croissant et ensuite décroissant) (Fig. 4H) et enfin hélices à tour de spire lâche (Fig. 4H,I). Le diamètre des filaments et leur organisation correspondent assez bien à celles des actinomycètes. La présence des hélices suggère un rapprochement avec les hyphes aériens du genre Streptomyces connus notamment chez l'espèce actuelle Streptomyces coelicolor Muller 1908. La morphologie des hyphes observée dans l'ambre de Belcodène est en effet très semblable à celle figurée par Waksman (1961) et Soliveri et al. (1993). Les hyphes à terminaisons en hélice correspondent à des « coiled sporogenous hyphae ». Les hélices observées dans l'ambre de Belcodène ne sont pas fragmentées, ce qui indiquerait un stade précédant la sporulation. Dans le cycle de vie des Streptomyces, la fragmentation des hyphes aériens est suivie par la maturation des spores et ensuite par la sporulation. Cependant cette absence apparente pourrait aussi être due à un biais taphonomique. Des hyphes aériens inclus d'actinomycètes sont ainsi signalés pour la première fois dans l'ambre santonien. 


\subsubsection{Actinomycètes $D$}

Ces filaments ont été observés à la périphérie des grains d'ambre translucides. Il s'agit de filaments de très petite taille, d'environ $0,7 \mu \mathrm{m}$ de diamètre, avec une apparence de zig-zag qui résulte en fait d'un style de ramification très serré (Fig. $4 \mathrm{~J})$. De très petites branches de 0,5 $\mu \mathrm{m}$ de longueur sont disposées en effet de manière alternée sur les deux cotés du filament. La distance entre les branches est d'environ $5 \mu \mathrm{m}$. L'organisation des filaments et leurs dimensions sont très semblables celles des actinomycètes. Des filaments similaires ont été décrits dans l'ambre sparnacien de l'Aude (Nocardia? par Breton, 2010) et dans l'ambre santonien de Martigues (Morphotype D par Saint Martin et al., 2012).

\subsubsection{Bactéries à gaine}

Dans les parties opaques des grains d'ambre, des ensembles de filaments constituent des arbuscules pouvant atteindre $200 \mu \mathrm{m}$ d'extension, très nettement envahissants vers l'intérieur (Fig. 5A). Il s'agit de filaments ayant un diamètre 1-1,5 $\mu \mathrm{m}$ (Fig. 5B). Des ramifications dichotomiques interviennent de manière régulière selon un angle d'environ $50-80^{\circ}$. Les filaments peuvent présenter un enroulement spiralé lâche (Fig. 5C). Dans certaines portions de grains d'ambre, les filaments acquièrent un manchon très visible, au diamètre régulier le long des filaments de 2-2,5 $\mu \mathrm{m}$, de couleur rouge-orange, avec un aspect rugueux. Ce phénomène est particulièrement marqué au niveau d'agglomérats très sombres rougeâtres, renfermant parfois des éléments framboïdes (Fig. 5E). On observe ainsi une gradation entre des zones à filaments arbusculaires à manchon absent (ou peu apparent), des secteurs où apparaissent des manchons plus ou moins continus (Fig. 5F) et la proximité des zones sombres où les manchons sont alors bien développés et accompagnés éventuellement d'épaississements bourgeonnants (Fig. 5G). Afin de déterminer au mieux la nature du manchon, un examen au microscope confocal à épifluorescence laser a été effectué. Une autofluorescence nette, signant un composé organique, est observée au niveau du filament. Par contre le manchon ne montre absolument aucune autofluorescence, ce qui atteste sa nature inorganique (Fig. 5H). Les images réalisées en mode réflexion montrent, normalement, une forte réflexion au niveau de la surface du manchon, mais aussi dans le cœur du filament. Trois éléments cylindriques apparaissent ainsi emboîtés : une partie centrale réfléchissante d'un diamètre de 0,4-0,5 $\mu \mathrm{m}$ pouvant correspondre à un lumen rempli de substances minérales, un filament organique et un manchon inorganique. La couleur rouge foncée en microscopie 
optique du manchon peut être due à une forte concentration en fer comme le montrent sans doute également les agglomérats d'éléments framboïdes dans certaines zones.

La présence du manchon semble indiquer la capacité des filaments à constituer une enveloppe homogène suggérant ainsi une bactérie à gaine. Plusieurs bactéries, comme Leptothrix, Sphaerotilus ou Gallionella, sont connues pour leur capacité d'oxyder le fer et/ou le manganèse ("iron bacteria"); les produits de ces réactions se retrouvent sous forme d'incrustations au niveau de la gaine. Dans l'ambre fossile du Crétacé, Schmidt \& Schaeffer (2005) ont décrit Leptotrichites resinatus, une bactérie à gaine aux caractéristiques proches de Leptothrix. Les dimensions des filaments de l'ambre de Belcodène sont cependant nettement plus faibles que Leptotrichites dont la gaine ne présente pas les mêmes caractéristiques que le manchon décrit ici, irrégulièrement réparti et ne se formant que sur certaines parties des mycéliums. En l'absence d'informations plus précises et de comparaisons satisfaisantes, il est possible que ces réseaux de filaments à manchons représentent le développement de bactéries, non déterminables en l'état, mais concentrant éventuellement le fer (et/ou le manganèse), un peu à la manière des "iron bacteria" actuelles.

\subsection{6. ?Bacterium A}

Ces filaments très fréquents sont observables uniquement à la périphérie rouge des grains en forme de goutte (Fig. 6A). Ils se présentent sous la forme de rubans torsadés d'environ 1,5 $\mu \mathrm{m}$ de largeur et peuvent atteindre une longueur de 30-50 $\mu \mathrm{m}$ (Fig. 6B). Les torsades se répètent avec un intervalle de 10-15 $\mu \mathrm{m}$. Les rubans sont affectés de divisions dichotomiques selon un angle proche de $70^{\circ}-80^{\circ}$. Certains des rubans montrent des structures monoverticillées leur conférant un aspect en étoile caractéristique (Fig. 6B). Les branches du verticille sont au nombre de 4 à 6 pour une longueur allant jusqu'à $15 \mu \mathrm{m}$. La densité des filaments diminue à partir de la périphérie. Ces filaments ont jusqu'à présent seulement été décrits dans l'ambre santonien de Martigues (Saint Martin et al., 2012) comme Morphotype E. Leur identification, malgré leur abondance, reste délicate à établir. La taille des filaments et la structure d'ensemble semblent plutôt les rattacher à des bactéries, des structures verticillées étant connues chez des actinomycètes comme Streptoverticillum.

\subsection{Champignons filamenteux}

Ils sont présents, à l'intérieur des grains d'ambre, suivant souvent des contacts entre différents flux de résine. Les filaments sont septés et colorés en jaune-orange. Ils ont un 
diamètre de 2-3 $\mu \mathrm{m}$ et présentent souvent des gonflements (épaississements) ou des constrictions (Fig. 6C-E). Ces filaments, constitués de cellules rectangulaires de 8-15 $\mu \mathrm{m}$ de longueur, sont parfois prolongés par des chaînes de cellules ovoïdes de 6-8 $\mu \mathrm{m}$ de longueur et 4-5 $\mu \mathrm{m}$ en diamètre (Fig. 6C-E). L'ensemble de ces caractéristiques suggère un champignon filamenteux. Des hyphes septés similaires sont signalés dans l'ambre du Crétacé d'Espagne (Martín-Gonzáles et al., 2009), dans l'ambre Albien-Cenomanien du sud-ouest de la France, (Girard et al., 2009d ; Girard, 2010 ; Girard et Adl, 2011) et dans l'ambre Santonien de Martigues (Saint Martin et al., 2012). Ils ont été attribués à des champignons cladosporioïdes, mais des caractères similaires peuvent aussi être retrouvés chez de nombreux groupes de champignons et les attributions proposées par Girard (2010) et Saint Martin et al. (2012) demanderaient à être confirmées. En ce qui concerne le taxon de l'ambre de Belcodène, suivant les illustrations de Crouss et al. (2007) et Schubert et al. (2007), les branches filamenteuses septées pourraient représenter les conidiophores et les chaînes de cellules ovoïdes pourraient correspondre à des conidies.

\subsection{Formes indéterminées}

\subsubsection{Morphotype indéterminé 1}

Ce morphotype est représenté par des réseaux de longs filaments droits ou légèrement incurvés se subdivisant en faisceaux de filaments plus courts radiaires donnant une apparence de verticilles (Fig. 6F). Les filaments allongés ont un diamètre d'environ $1 \mu \mathrm{m}$ pour une longueur variable pouvant atteindre 80-100 $\mu \mathrm{m}$. Les faisceaux rayonnants sont constitués de filaments de 1-2 $\mu \mathrm{m}$ de diamètre, certains de forme lancéolée. Les dimensions des filaments et l'aspect en faisceaux pourraient suggérer les hyphes aériens de certains actinomycètes de type Streptoverticillium.

\subsubsection{Morphotype indéterminé 2}

Ce morphotype se caractérise par une grande densité de touffes jointives en pelotes atteignant $200 \mu \mathrm{m}$ de diamètre et formées de très fins filaments enchevêtrés (Fig. 6G-H). Les filaments de l'ordre de 0,5-0,8 $\mu \mathrm{m}$ de diamètre peuvent former des structures plus ou moins radiaires ou en faisceaux et atteindre une longueur de $50 \mu \mathrm{m}$. Ce morphotype évoque la croissance d'un mycélium filamenteux de microorganismes de type actinomycète occupant de façon optimale le substrat nutritif. 


\section{Discussion}

\subsection{Préservation des filaments de Belcodène}

Dans l'ambre de Belcodène, les micro-inclusions filamenteuses sont très similaires à celles décrites dans l'ambre de Martigues (Saint Martin et al., 2012), incluant des types de filaments bactériens (Actinomycètes A, B et D, Bacterium A) et fongiques (champignons filamenteux) très comparables dans les deux ambres. A Belcodène, pour la première fois dans l'ambre santonien, la présence d'hyphes aériens attribués à des actinomycètes de type Streptomyces est mise en évidence. Les occurrences d'hyphes aériens sont plutôt rares, mais néanmoins ont été déjà signalées par Breton (2010) dans l'ambre sparnacien des Corbières, (Aude) avec des « rameaux sporifères » appartenant aux genres Thermomonospora et Thermomonosporopsis et des conidies de Nocardia. Waggoner (1993) a aussi décrit des hyphes aériens dans l'ambre éocène des Etats-Unis. Il les avait déjà rapprochés du genre Streptomyces, ce qui suggère que cette bactérie devait être un des principaux organismes résinicoles du Santonien.

La distribution des différents types de filaments dans l'ambre de Belcodène confirme les observations réalisées sur l'ambre santonien de Martigues (Saint Martin et al., 2012), sur l'ambre campanien du Mas d'Azil (Breton et al., ce volume), sur des ambres d'âges variés de gisements français (Girard, 2010 ; Breton, 2011). L’ambre peut ainsi être considéré, selon Breton (2011), comme un milieu de culture fossilisé. Le caractère colonisateur de la majeure partie des réseaux de filaments observés est marqué par leur développement centripète, avec une densité décroissante, depuis le bord vers l'intérieur des morceaux d'ambre. Les sections polies effectuées à partir de nombreux grains d'ambre nous montrent qu'à la périphérie des gouttes initiales de résine s'installent et s'accroissent des mycéliums filamenteux de nature variée. Les actinomycètes $\mathrm{A}$ forment un très mince cortex issu en réalité de la coalescence de colonies sphériques (Girard, 2010). Les filaments de Bacterium A constituent également un cortex, rougeâtre en section, qui dans certains cas peut gagner largement vers le centre de la goutte (Fig. 2G). Comme à Martigues (Saint Martin et al., 2012), certains types de filaments caractérisent plutôt des types d'ambre particuliers. Ainsi, les filaments de bactérie à gaine (?) sont souvent rencontrés dans les morceaux d'ambre opaque, tandis que les gouttes d'ambre translucides renferment plutôt des filaments de Bacterium A et des Actinomycètes A, C et D. Malheureusement, l'origine précise de la différence d'opacité entre ces deux types d'ambre reste une énigme (cause environnementale, climatique et/ou biologique ?) et l'écologie plus précise de ces différents organismes filamenteux est difficile à préciser. Néanmoins, le 
développement de ces filaments, en l'absence de signes de distorsion et d'orientation préférentielle, plaide en faveur d'un développement « naturel » dans la résine liquide, permettant ainsi de définir un micromonde résinicole capable d'utiliser la résine liquide comme substrat et comme milieu nutritionnel. Des études sur les résines actuelles ont démontré ces aptitudes pour les actinomycètes, les bactéries à gaine ou bien des champignons filamenteux (Rikkinen, 2003 ; Rikkinen et Poinar, 2000, 2001 ; Brasier et al., 2009 ; Vargas Gill et al., 2009 ; Beimforde et Schmidt, 2011 ; Breton, 2012). Dans le cas de l'ambre de Belcodène, la colonisation a dû s'effectuer sur des coulées de résine produites au niveau du tronc, des branches ou des rameaux. En effet, l'absence d'organismes typiques de litières plaide en faveur de coulées de résine n'ayant jamais touché le sol et s'étant solidifiées sur le tronc. De plus la forme des grains d'ambre en gouttelettes est typique des coulées de résines produites au niveau des branches et qui acquièrent cette forme par gravité. Deux modes de colonisation des organismes filamenteux peuvent être envisagés. Dans le premier cas, les coulées ont pu être sécrétées dans un environnement humide, permettant le développement des organismes filamenteux pendant que les coulées de résine durcissaient. Cette hypothèse est concordante avec un environnement côtier comme celui qui semble être l'environnement de production de l'ambre de Belcodène. Dans le deuxième cas, les colonisations ont pu s'effectuer un peu plus tardivement après la sécrétion de résine. En effet, dans les forêts actuelles de résineux, il n'est pas rare qu'un voile bactérien blanchâtre se développe sur des coulées de résine ancienne. Il est possible que la colonisation de la résine ait suivi ces deux modalités, selon le type d'organismes impliqué, la rareté d'autres organismes piégés dans l'ambre de Belcodène pourrait cependant privilégier la seconde hypothèse.

\subsection{Origine, environnement de secrétion et milieu de dépôt de l'ambre de Belcodène}

Les sédiments santoniens de Belcodène renferment une grande quantité de grains d'ambre automorphes de petite taille, en forme de goutte, et plus rarement des microgalets. Cette caractéristique a déjà été mise en évidence pour les gisements santoniens de Martigues (Saint Martin et al. 2012), de Piolenc (Perrichot, 2005) et de l'Alabama (Knight et al., 2010). Bien que peu de travaux aient été effectués sur les ambres santoniens, il semble qu'il s'agisse d'une caractéristique plus fréquente pour les ambres du Crétacé supérieur, que pour ceux de l'Albo-

Cénomanien. Ces derniers sont en effet de taille généralement plus importante et correspondent plus à des galets d'ambre plus ou moins remaniés en milieu aquatique (Perrichot, 2005 ; Girard, 2010 ; Najarro et al., 2009, 2010) qu'à des coulées automorphes. 
L'interprétation de ces différences pourrait permettre une meilleure compréhension des modalités d'installation des microcénoses filamenteuses définies plus haut, voire de leur composition. La part des processus impliqués dans la genèse des gisements d'ambre est difficile à déterminer précisément et selon Knight et al. (2010) la comparaison entre des gisements de provenance et d'âge différents reste très délicate. Plusieurs types d'explications non exclusives pourraient donc être avancées à ces différences: 1) une origine botanique différente; 2) l'influence de l'environnement de sécrétion de la résine; 3) les conséquences d'un stress événementiel; 4) les conditions de formation et l'histoire taphonomique.

En ce qui concerne l'origine botanique de l'ambre de Belcodène, aucune étude directe n'a été jusqu'à présent réalisée. Le matériel ligniteux retrouvé au sein du sédiment est en général de trop petite taille et ne permet pas une identification directe aisée. Les caractéristiques biogéochimiques de l'ambre peuvent alors fournir un élément de réponse. Onoratini et al. (2009a), sur la base de données de spectroscopie IRTF, ont montré que l'ambre de Belcodène a des caractéristiques chimiques semblables à celles des autres ambres santoniens du SE de la France. Ils ont ainsi mis en évidence la présence de groupements carbonyle de type acide carboxylique dans les ambres santoniens. D'autres différences entre la distribution des fonctions oxygénées ont également été observées entre les ambres albo-cénomaniens et santoniens. Selon Guiliano et al. (2006) et Onoratini et al. (2009b) ces différences pourraient s'expliquer par le remplacement des forêts à Araucariacées par des forêts à Angiospermes. Pour Ragazzi et al. (2009), les analyses thermiques menées sur les ambres santoniens, dont celui de Belcodène, suggèrent une origine ou des conditions taphonomiques communes, peutêtre également en liaison avec la dominance à cette époque d'une flore à angiospermes (Gomez et al., 2003). Néanmoins, il est intéressant de noter que les ambres santonien de Belcodène (Onoratini et al., 2009a) et cénomanien des Charentes (Perrichot, 2005; Néraudeau et al., 2012) présentent des spectres très similaires. Or Perrichot (2005) a permis d'identifier la plante productrice de l'ambre des Charentes comme étant une Araucariaceae ou une Cheirolepidiaceae. Ces similitudes plaident en faveur de l'hypothèse taphonomique pour expliquer les caractéristiques observées par Guiliano et al. (2006) et Onoratini et al. (2009b). L'origine de l'ambre de Belcodène pourrait donc être recherchée parmi les conifères qui peuplaient la région au Santonien. L'absence de restes de Fabaceae (Gomez et al., 2003) et l'identification récente de restes de Cheirolepidiaceae du genre Frenelopsis dans la flore santonienne de Piolenc (Bernard Gomez, pers. com.) appuient l'hypothèse d'une origine coniférienne de l'ambre santonien du Sud-Est de la France. En effet les arbres de cette famille sont supposés être parmi les principaux sécréteurs de résine du Crétacé moyen en Europe 
(Perrichot, 2005, Néraudeau et al., 2008, Najarro et al., 2010, Menor-Salván et al. 2010). Ainsi, l'hypothèse de productions résinifères issues de groupes botaniques bien différenciés reste difficile à étayer dans l'état actuel des connaissances, Araucariaceae et Cheirolepidiaceae étant des arbres ambrifères potentiels dans un cas stratigraphique comme dans l'autre. Toutefois, on peut noter qu'au sein des Araucariaceae actuelles, certaines espèces comme Agathis robusta (C. Moore ex F. Muell.) F.M. Bailey produisent des coulées résineuses très volumineuses, tandis que d'autres, comme Araucaria heterophylla (Salisb.) Franco, ne forment au mieux que des gouttelettes ou de fines stalactites. Des arbres phylogénétiquement proches, et partageant des bois qui pourraient rester indifférenciés à l'état fossile (ex : Araucarioxylon, cf. Philippe, 2011), pourraient donc être les auteurs respectifs des ambres médio-crétacés et fini-crétacés, mais producteur de grosse coulées pour une espèce et de petites gouttes résineuses pour l'autre.

Si l'ambre de Belcodène résulte, comme la plupart des ambres du Crétacé, de secrétions de conifères, l'environnement de ces sécrétions peut avoir eu une influence sensible. En ce qui concerne les ambres albo-cénomaniens français et espagnols, il a été envisagé que certains d'entre eux avaient été produits par des Araucariaceae/Cheirolepidiaceae poussant en environnement côtier (Vonk et Schram, 2007, Girard et al., 2008, 2009c,d, Girard, 2010). En Espagne, selon Najarro et al. (2010) l'ambre, collecté dans des sédiments marins, est lui aussi un matériel parautochtone issu de la sécrétion de résine d'Araucariaceae/Cheirolepidiaceae dans un environnement de type deltaïque. En ce qui concerne les ambres santoniens français, l'environnement de sécrétion reste encore mal défini. A Belcodène comme à Martigues (Saint Martin et al., 2012), les environnements de dépôt étant marins et la majorité des grains d'ambre automorphes, l'arbre producteur de résines devait se développer dans un environnement côtier, ce qu'indique aussi l'encadrement des couches à ambres par des faciès construits à rudistes. Coiffard et al. (2006) ont montré que les gymnospermes, notamment les Cheirolepidiaceae, dominaient à l'Albien et au Cénomanien les environnements liés aux eaux saumâtres. Les résineux semblent avoir été alors très stimulés par les contraintes environnementales (fort taux de salinité édaphique et /ou xéricité) pour produire de très fortes quantités de résine s'exprimant notamment par des agglomérats volumineux de coulées de résines. Ainsi il le renouvellement floristique au niveau des environnements côtiers entre l'Albien/Cénomanien et le Santonien, a peut-être été marqué par le déplacement en zone interne plus protégée des conifères de type Araucariaceae/ Cheirolepidiaceae et de la colonisation des zones externes plus soumises à l'influence marine par les angiospermes. Au final, les gouttelettes de résine majoritairement représentées à Belcodène pourraient être la 
résultante d'une diminution des pressions environnementales sur les résineux ambrifères, Araucariaceae et/ou Cheirolepidiaceae, en liaison avec le renouvellement floristique important survenu au Crétacé supérieur. Cependant il faut noter que le genre Frenelopsis était, dès l'Albien, adapté, selon les espèces, à un large éventail d'habitats allant des plaine d'inondation côtières à caractère saumâtre à de l'eau douce de l'intérieur (Gomez et al., 2002), même si leur habitat principal restait le domaine côtier (Coiffard et al. 2006). D’autre part, on connaît dans le Cénomanien inférieur charentais des dépôts littoraux exceptionnellement riches en angiospermes et recouvrant des lignites ambrifères à Cheirolepidiaceae (carrière de Puy-Puy à Tonnay-Charente ; Gomez et al., 2004, Néraudeau et al., 2005). L'opposition Crétacé moyen/Crétacé supérieur n'est donc peut-être pas totalement liée à l'importance de la diversité des angiospermes à ces deux périodes, mais plutôt au milieu de dépôt de leurs ambres respectifs. Par ailleurs les gisements du Cénomanien supérieur (Saint Martin et al., ce volume) et du Turonien (D. Néraudeau obs. pers.) de Dordogne possèdent déjà les mêmes caractéristiques que ceux du Santonien avec une grande abondance de gouttelettes de très petite taille.

La taille des coulées de résine et des nodules d'ambre qui en résultent pourrait également être fonction des perturbations environnementales qui auraient agressé les résineux. Ainsi a été évoquée par divers auteurs la fréquence au Crétacé inférieur et moyen de tempêtes ou/et d'incendies de forêts (Brasier et al., 2009, Martill et al., 2012) qui auraient fortement blessé les arbres ambrifères et ainsi conduit à d'abondantes et volumineuses coulées de résine. Des perturbations comparables étant peu documentés au Santonien, cela pourrait expliquer une production ambrifère plus rare et moins volumineuse à cette seconde période.

Tout gisement ambrifère possède des caractéristiques résultant d'une histoire biologique et sédimentaire propre, le milieu de formation de la résine pouvant, dans certains cas, être éloigné du milieu de dépôt (Martill et al., 2005). Dès le Crétacé inférieur deux types morphologiques de grains d'ambre peuvent être distingués dans les gisements: des nodules parfois de très grande taille et des grains en forme de gouttes, plus ou moins stalactitiques (Peňalver et al., 2007). La dominance de l'un ou l'autre type dans les dépôts pourrait aussi résulter d'une histoire taphonomique diversifiée, comme illustrée par Martinez-Delclos et al. (2004). Les ambres santoniens de Belcodène et de Martigues ont en commun le même contexte sédimentaire, caractérisé par la présence de nombreux organismes marins (foraminifères, coraux, gastéropodes, rudistes et autres bivalves, échinodermes), y compris dans les couches les plus riches en ambre. Il s'agit donc de coulées résineuses qui ont été transportées par l'eau (microgalets) en milieu marin côtier ouvert où elles se sont déposées 
après plus ou moins de ballottement par les vagues et sur le fond. Très peu de gisements d'ambres albo-cénomaniens des Charentes présentent des conditions de dépôt comparables, la plupart étant des lignites déposés en milieu estuarien avec des galets d'ambre fortement roulés et bien souvent perforés par des lithophages (Néraudeau et al., 2002). Toutefois, le gisement d'ambre le plus occidental des Charentes, situé à Chaucres sur l'île d'Oléron, correspond à un calcaire marin du Cénomanien inférieur médian (unité B2 sensu Néraudeau et al. 1997) dans lequel les grains d'ambre sont peu fréquents et de petite taille $(<1 \mathrm{~cm})$ et associés à divers invertébrés marins (brachiopodes, céphalopodes, échinides, lamellibranches) (Néraudeau, 2008). Le même faciès marin franc à ambre a aussi été identifié (D.N., obs. pers.) dans la même unité stratigraphique sur le site de La Varenne à Tonnay-Charente, associé là-encore à des brachiopodes et des échinides. Les gisements strictement contemporains situés plus au sud-est, comme à La Buzinie près d'Angoulême (Perrichot et al., 2007), correspondent à des milieux de dépôt plus côtiers, marqués par l'abondance des huîtres paraliques (Striostrea sp.) et des microrestes de vertébrés dont des dinosaures. Dans ces faciès plus proximaux, l'ambre se trouve sous forme de gros galets pluricentimétriques à décimétriques. L'abondance des grains en forme de gouttes pourrait ainsi s'expliquer par une plus grande facilité de transport et de concentration plus éloigné de la zone de production. A Belcodène, la présence d'un ciment marin entourant les gouttelettes déjà solidifiées peut signifier ainsi une résidence dans l'eau de mer avant le dépôt. Au contraire, on peut être amené à sous-évaluer la présence de coulées plus importantes immobilisées, voir adhérentes, sur le tronc ou au pied des arbres producteurs et donc peu transportées et sédimentées. Tout grain éloigné de son arbre et/ou lieu de production, pouvant être redistribué selon les conditions de transport, un biais taphonomique déjà souligné par Pike (1993), est introduit aussi bien pour la représentativité des types de grains que, finalement, les microcénoses relevées.

Il apparaît donc finalement que la taille des grains d'ambre crétacé récoltés peut tout à fait être dépendante de leur origine botanique, de leur mode de formation (gouttelettes ou coulées) ou du lieu de la production résinicole, mais peut être plus simplement fonction de l'histoire des productions résinifères depuis leur milieu de formation jusqu'au milieu de dépôt, et donc de l'intensité du transport et de la fragmentation et du temps de résidence dans le milieu de dépôt avant l'enfouissement. Tant au Crétacé moyen qu'au Crétacé supérieur, les grains d'ambre sont de petite taille dans des faciès marins francs. A l'Albo-Cénomanien, ils sont de grande taille en milieux estuarien et paraliques. L'équivalent de ces milieux au Santonien resterait à mieux connaître. 


\section{Conclusion}

Contrairement à leurs homologues albien/cénomanien, les écosystèmes ambrifères du Santonien ont été peu étudiés. Le développement de l'étude des microorganismes de l'ambre, et notamment des filaments, permet de combler ce manque et de mieux appréhender l'évolution des ces écosystèmes durant le Crétacé supérieur.

L'ambre de Belcodène est très semblable celui de Martigues, tant par la forme des grains d'ambre retrouvés dans ces gisements que par la microflore filamenteuse préservée. L'ensemble des observations faites sur les deux gisements (Saint Martin et al., 2012, cette étude) suggère un vrai monde résinicole installé sur la résine encore liquide en l'utilisant probablement à la fois comme support et comme source de nutriments. Au contraire de certains ambres cénomaniens, aucun signe de piégeage au sol n'a pas être mis en évidence. Cette absence est peut être à relier à la prédominance de suintements d'ambres dans les parties aériennes des plantes et au changement floristique qui a eu lieu au début du Crétacé supérieur. En effet, le développement des angiospermes et la compétition qu'il a engendrée a pu repousser les arbres producteurs de résines (Araucariaceae/Cheirolepidiaceae) des environnements côtiers à influence saumâtre vers des parties internes plus protégées où les conditions étaient plus favorables pour eux, réduisant ainsi la quantité de production de résine. Néanmoins cette hypothèse est à modérer car l'hypothèse d'un tri par transport ne peut être écartée.

Les niveaux santoniens à ambre ne sont pas si rares comme le montrent des travaux récents (Perrichot, 2005; Knight et al., 2010; Saint Martin et al., 2012; cette étude). La multiplication des études de ces niveaux nous renseignera sur des écosystèmes forestiers encore peu connus et qui ont, sans doute, beaucoup à nous apprendre sur la révolution floristique qui s'est déroulée au Crétacé supérieur.

\section{Remerciements}

Lilian Cazes (MNHN) a assuré la réalisation des lames minces spécifiques au matériel particulier que constitue l'ambre. Les observations au MEB ont été effectuées grâce à l'amicale assistance de Roger Notonier et Alain Tonetto (Aix-Marseille Université). Nous remercions Suzanne Bolte de la Plate-forme d'Imagerie Cellulaire et Cytométrie en Flux de l'IFR83 (Université Paris 6) pour son aide précieuse au Microscope Confocal, cette installation étant prise en charge par le Conseil régional d'Ile-de-France. Bernard Gomez (Université Claude Bernard Lyon 1) nous a aimablement fait bénéficier de ses connaissances 
sur la flore santonienne régionale. Nous remercions Yves Dutour et Eric Turini (Muséum d'Histoire Naturelle d'Aix-en-Provence) pour nous avoir guidés sur le terrain et pour la mise à disposition du matériel qu'ils ont récolté lors de leurs fouilles sur les niveaux ambrifères. Nous sommes redevables à VINCI Autoroutes (réseau Escota) et particulièrement à Samuel Maurice, Responsable Juridique en Environnement et Développement Durable Projets d'Infrastructures, pour nous avoir aimablement facilité l'accès à l'affleurement situé sur le domaine autoroutier. Ces recherches ont été réalisées dans le cadre du programme CNRSINSU INTERRVIE NOVAMBRE 2 et de l'ATM (Action Transversale du Muséum National d'Histoire Naturelle) Biodiversité et rôle des microorganismes dans les écosystèmes actuels et passés.

\section{Références bibliographiques}

Ascaso, C., Wierzchos, J., Corral, C.J., Lopez, R., Alonso, J., 2003. New application of light and electron microscopic techniques for the study of microbial inclusions in amber. Journal of Paleontology 77, 986-996.

Beimforde, C., Schmidt, A.R., 2011. Microbes in resinous habitats: a compilation from modern and fossil resins. In: Reitner G. et al (Eds), Advances in Stromatolite geobiology, Lectures Notes in Earth Sciences 131, 391-407.

Brasier, M., Cotton, L., Yenney, Y., 2009. First report of amber with spider webs and microbial inclusions from the earliest Cretaceous (c. $140 \mathrm{Ma}$ ) of Hastings, Sussex. Journal of the Geological Society of London 166, 989-997.

Breton, G., 2010. Les Actinomycètes de l'ambre Sparnacien des Corbières (Aude, France) : taphonomie et diversité. Annales de la Société Géologique du Nord 17 (2), 3-22.

Breton, G., 2011. L'ambre, un milieu de culture fossilisé. Bulletin de la Société d'Étude des Sciences Naturelles d'Elbeuf $2^{\text {ème }}$ trimestre 2011, 28-29.

Breton, G., 2012. L'ambre des Corbières (Aude-France), SESA, Carcassonne, 96 p.

Breton, G., Bilote, M., Eychenne, G., 2013. L'ambre campanien du Mas d'Azil (Ariège, France) : gisement, microinclusions, taphonomie. Annales de Paléontologie, ce volume.

Breton, G., Tostain, F., 2005. Les microorganismes de l'ambre cénomanien d'Ecommoy (Sarthe, France). Comptes Rendus Palevol 4, 31-46.

Coiffard, C., Gomez, B., Kvaček, J., Thévenard, F., 2006. Early angiosperm ecology : évidence from the Albian-Cenomanian of Europe. Annals of Botany 98, 495-502.

Collot, L., 1890. Description du terrain crétacé dans une partie de la Basse-Provence. Bulletin de la Société géologique de France 18, 49-102. 
Crous, P.W., Braun, U., Schubert, K., Groenewald, J.Z., 2007. Delimiting Cladosporium from morphologically similar genera. Studies in Mycology 58, 33-56.

Girard, V., 2009. Evidence of Scenedesmaceae (Chlorophyta) from 100 million-year-old amber. In: Perrichot, V., Néraudeau, D., (Eds.) Cretaceous ambers from southwestern France: geology, taphonomy and paleoecology. Geodiversitas 31, 145-152.

Girard, V., 2010. Microcénoses des ambres médio-crétacés français. Taphonomie, systématique, paléoécologie et reconstitution du paléoenvironnement. Mémoires Géosciences Rennes 134, 1-294.

Girard, V., Schmidt, A.R., Saint Martin, S., Struwe, S., Perrichot, V., Saint Martin, J.-P., Grosheny, D., Breton, G., Néraudeau, D., 2008. Evidence for marine microfossils from amber. Proceedings of the National Academy of Sciences of the United States of America $105,14426-17429$.

Girard, V., Breton, G., Brient, L., Néraudeau, D., 2009a. Sheathed prokaryotic filaments, major components of Mid-Cretaceous French amber microcoenoses. Journal of Paleolimnology 42, 437-447.

Girard, V., Néraudeau, D., Breton G., Saint Martin, S., Saint Martin, J.-P. 2009b. Contamination of amber samples by recent microorganisms and remediation evidenced by Mid-Cretaceous amber of France. Geomicrobiology Journal 26, 1, 21-30.

Girard, V., Saint Martin, S., Saint Martin, J.P., Schmidt, A.R., Struwe, S., Perrichot, V., Breton, G., Néraudeau, D., 2009c. Exceptional preservation of marine diatoms in Upper Albian amber. Geology 37, 83-86.

Girard, V., Schmidt, A.R., Struwe, S., Perrichot, V., Breton, G., Néraudeau, D., 2009d. Taphonomy and palaeoecology of mid-Cretaceous amber-preserved microorganisms from southwestern France. In: Perrichot, V., Néraudeau, D., (Eds) Cretaceous ambers from southwestern France: geology, taphonomy and paleoecology. Geodiversitas 31, 153-162.

Girard, V., Adl, S.M., 2011. Amber microfossils: on the validity of species concept. Comptes Rendus Palevol 10, 189-200.

Gomez, B., Barale, G., Saad, D., Perrichot, V., 2003. Santonian Angiosperm-dominated leafassemblages from Piolenc (Vaucluse, Sud-Est de la France). Comptes Rendus Palevol 2, 197-204.

Gomez, B., Daviero-Gomez, V., Perrichot, V., Thévenard, F., Coiffard, C., Philippe, M., Néraudeau, D., 2004. Meso- and megaremains of fossil plants from the AlbianCenomanian of Charente-Maritime (SW France). Annales de Paléontologie 90, 147-159. 
Gomez, B, Martín-Closas, C, Barale, G, Solé de Porta, N., Thévenard, F, Guignard, G. 2002. Frenelopsis (Coniferales: Cheirolepidiaceae) and related male organ genera from the Lower Cretaceous of Spain. Palaeontology 4, 997-1036.

Guiliano, M., Mille, G., Onoratini, G., Simon, P., 2006. Présence d'ambre dans le Crétacé supérieur (Santonien) de La Mède à Martigues (Sud-Est de la France); caractérisation IRTF. Comptes Rendus Palevol 5, 851-858.

Holt, J.G., Krieg, N.R., Sneath, J.T., Williams, S.T., 2000. Bergey's manual of determinative bacteriology. Ninth edition, Lippincott Williams and Wilkins, Philadelphia. 787 pp.

Knight, T.K., Bingham, P.S., Grimaldi, D.A., Anderson, K., Lewis, R.D., Savrda, C.E., 2010. A new Upper Cretaceous (Santonian) amber deposit from the Eutaw Formation of eastern Alabama, USA. Cretaceous Research 31, 85-93.

Martill, D.M., Loveridge, R.F., Andrade, J.A.F.G., Herzog Cardosa, A., 2005. An unusual occurrence of amber in laminated limestones: the Crato Formation Lagerstätte (Early Cretaceous) of Brazil. Palaeontology 48, 1399-1408.

Martill, D.M., Loveridge, R.F., Mohr, B.A.R., Simmons, E., 2012. A wildfire origin for terrestrial organic debris in the Cretaceous Santana Formation Fossil Lagerstätte (Araripe Basin) of north-east Brazil. Cretaceous Research 34, 135-141.

Martín-Gonzáles, A., Wierzchos, J., Gutiérrez, J.C., Alonso, J., Ascaso, C., 2008. Morphological stasis of protists in Lower Cretaceous amber. Protist 159, 251-336.

Martín-Gonzáles, A., Wierzchos, J., Gutiérrez, J.C., Alonso, J., Ascaso, C., 2009. Microbial Cretaceous park: biodiversity of microbial fossils entrapped in amber. Naturwissenschaften 96, 551-564.

Martínez-Delclòs, X., Briggs, D.E.G., Peňalver, E., 2004. Taphonomy of insects in carbonates and amber. Palaeogeography, Palaeoclimatology, Palaeoecology 203, 19-64.

Menor-Salván, C., Najarro, M., Velasco, F., Rosales, I., Tornos, F., Simoneit, B.R.T., 2010. Terpenoids in extracts of Lower Cretaceous ambers from the Basque-Cantabrian Basin (El Soplao, Cantabria, Spain): Paleochemotaxonomic aspects. Organic Geochemistry 41, 1089-1103.

Najarro, M., Peñalver, E., Rosales, I, Péreez de la Fuente, R., Daviero-Gomez, V., Gomez, B., Delclòs, X., 2009. Unusal concentration of Early Albian arthropod-bearing amber in the Basque-Cantabrian Basin (El Soplao, Cantabria, Northern Spain): Palaeoenvironmental and palaeobiological implications. Geologica Acta 7, 363-387.

Najarro, M., Peñalver, E., Pérez de la Fuente, R., Ortega-Blanco, J., Menor-Salván, C., Barrón, E., Soriano, C., Rosales, I., López del Valle, R., Velasco, F., Tornos, F., Daviero, 
Gomez, V., Gomez, B., Delclòs, X., 2010. Review of the El Soplao amber outcrop, Early Cretaceous of Cantabria, Spain. Acta Geologica Sinica 84, 959-976.

Nel, A., de Ploëg, G., Menier, J.-J., Waller, A., 2004. The French ambers: a general conspectus and the Lowermost Eocene amber deposit of Le Quesnoy in the Paris Basin. Geologica Acta 2, 3-8.

Néraudeau, D., 2008. Les lignites à ambre de l'archipel charentais. Bulletin de l'A.M.A.R.A.I. $21,5-15$.

Néraudeau, D., Manem, S., Delclos, X., Girard, V., 2012. L’ambre crétacé des Charentes: une alternative à l'ambre balte. In : Marchand, G., Querré, G. (Eds.), Roches \& Sociétés de la Préhistoire, Presses universitaire de Rennes, pp. 265-271.

Néraudeau, D., Perrichot, V., Colin, J.-P., Girard, V., Gomez, B., Guillocheau, F., Masure, E., Peyrot, D., Tostain, F., Videt, B., Vullo, R., 2008. A new amber deposit from the Cretaceous (uppermost Albian-lowermost Cenomanian) of southwestern France. Cretaceous Research 29, 925-929.

Néraudeau, D., Perrichot, V., Dejax, J., Masure, E., Nel, A., Philippe, M., Moreau, P., Guillocheau, F., Guyot, T., 2002. Un nouveau gisement à ambre insectifère et à végétaux (Albien terminal probable): Archingeay (Charente-Maritime, France). Géobios 35, 233 240.

Néraudeau, D., Thierry, J., Moreau, P., 1997. Variations of echinoids biodiversity during the Cenomanian-Early Turonian transgressive episode in Charentes (France). Bulletin de la Société géologique de France 168(1), 51-61.

Néraudeau, D., Vullo, R., Gomez, B., Perrichot, V., Videt, B., 2005. Stratigraphie et paléontologie (plantes, vertébrés) de la série margino-littorale Albien terminal Cénomanien basal de Tonnay-Charente (Charente-Maritime, France). Comptes Rendus Palevol 4, 79-93.

Onoratini, G., Guiliano, M., Asia, L., Mille, G., Simon, P., 2009a. L'ambre dans le Sud-Est de la France, ressources géologiques et utilisation archéologique. Bulletin du Musée d'Anthropologie préhistorique de Monaco 49, 3-20.

Onoratini, G., Guiliano, M., Mille, G., Simon, P., 2009b, L’ambre albo-cénomanien de la montagne de Lure (Alpes-de-Haute-Provence), outil stratigraphique et paléogéographique. Geobios 42, 89-99.

Peňalver, E., Delclòs X., Soriano C., 2007 A new rich amber outcrop with palaeobiological inclusions in the Lower Cretaceous of Spain. Cretaceous Research 28,791-802. 
Perrichot, V., 2005. Environnements paraliques à ambre et à végétaux du Crétacé nordaquitain (Charentes, Sud-Ouest de la France). Mémoires Géosciences Rennes 118, 1-310.

Perrichot, V., Nel, A., Néraudeau, D., 2007. Schizopterid bugs (Insecta: Heteroptera) in MidCretaceous ambers from France and Myanmar. Palaeontology 50(6), 1367-1374.

Perrichot, V., Néraudeau, D., Nel, A., de Ploëg, G., 2007. A reassessment of the Cretaceous amber deposits from France and their palaeontological significance. African Invertebrates $48,213-227$.

Philip, J., 1974. Les formations calcaires à Rudistes du crétacé supérieur provençal et rhodanien : stratigraphie et paléogéographie. Bulletin du B.R.G.M. section I, 3, 107-151.

Philippe, M., 2011. How many species of Araucarioxylon? Comptes Rendus Palevol 2-3, 201-208.

Pike, E. 1993. Amber taphonomy and collecting biases. Palaios 8, 411-419.

Poinar G.O.Jr., Buckley R., 2007. Evidence of mycoparasitism and hypermycoparasitism in Early Cretaceous amber. Mycological Research 3, 503-506.

Ragazzi, E., Giaretta, A., Perrichot, V., Néraudeau, D., Schmidt, A. R., Roghi, G., 2009. Thermal analysis of Cretaceous ambers from southern France. Geodiversitas 31, 163 175.

Rikkinen, J., 2003. New resinicolous ascomycetes from beaver scars in western North America. Annales Botanici Fennici 40, 443-450.

Rikkinen, J., Poinar, G.O.Jr, 2000. A new species of resinicolous Chaenothecopsis (Mycocaliciaceae, Ascomycota) from 20 million year old Bitterfeld amber, with remarks on the biology of resinicolous fungi. Mycological Research 1, 7-15.

Rikkinen, J., Poinar, G.O.Jr., 2001. Fossilised fungal mycelium from tertiary Dominican amber. Mycological Research 105, 890-896.

Saint Martin, S., Saint Martin, J.-P., Girard, V., Grosheny, D., Néraudeau, D., 2012. Filamentous micro-organisms in Upper Cretaceous amber (Martigues, France). Cretaceous Research 35, 217-229.

Schmidt A.R., Schäfer, U., 2005. Leptotrichites resinatus new genus and species: a fossil sheathed bacterium in Alpine Cretaceous amber. Journal of Paleontology 79, 175-184.

Schubert, K., Groenewald, J.Z., Braun, U., Dijsksterhuis, J., Starnik, M., Hill, C.F., Zalar, P., de Hoog, G.S., Crous, P.W., 2007. Biodiverity in the Cladosporium herbarum complex (Davidiellacea, Capnodiales), with standardisation of methods for Cladosporium taxonomy and diagnostics. Studies in Mycology 58, 105-156. 
Soliveri, J., Vijgenboom, E., Granozzi, C., Plaskitt, K.A., Chater, K.F., 1993. Functional and evolutionary implications of a survey of various actinomycetes for homologues of two Streptomyces coelicolor sporulation genes. Journal of General Microbiology 139, 25692578 .

Vargas Gil, S., Pastor, S; March, G.J., 2009. Quantitative isolation of biocontrol agents Trichoderma spp., Gliocladium spp. and actinomycetes from soil with culture media. Microbiological Research 164, 196-205.

Vasseur, G., 1894. Compte rendu d'excursions géologiques aux Martigues et à l'Estaque (Bouches-du-Rhône). Bulletin de la Société Géologique de France 22, 413-444.

Vonk, R., Schram, F.R., 2007. Three new tanaid species (Crustacea, Peracarida, Tanaidacea) from the Lower Cretaceous Álava amber in Northern Spain. Journal of Paleontology 81, 1502-1509.

Waggoner, B.M., 1993. Fossil actinomycetes and other bacteria in Eocene amber from Washington State, USA. Tertiary Research 14, 155-160.

Waggoner, B.M., 1994. Fossil actinomycete in Eocene-Oligocene Dominican amber. Journal of Paleontology 68, 398-401.

Waksman, S.A., 1961. The Actinomycetes vol II. Classification. Identification and descriptions of genera and species. The Wiliams \& Wilkins Company (Eds), Baltimore, $363 \mathrm{p}$. 


\section{Légendes des figures}

Figure 1. Cadre géographique et géologique. A. Situation du site d'étude en France. B. Coupe géologique. 1. Calcaire construit à rudistes, 2. Calcaire noduleux, 3. Marnes bleuâtres à faune marine, 4. Sables fossilifères à lignite et ambre, 5. Marnes feuilletées à lignite et ambre, 6 . Marnes sableuses jaunâtres. 7. Niveaux ambrifères. C. Aperçu de l'affleurement. 1. Calcaire à rudistes. 2. Niveaux ambrifères. 3. Sables jaunes.

Figure 1. Geographic and geological settings. A. Position of the studied area in France. $\boldsymbol{B}$. Geologic section. 1. Limestone with rudists, 2. Nodular limestone, 3. Bluish marls containing marine fauna, 4. Fossilerous sand with lignite and amber pieces, 5. Laminated marls with lignite and amber pieces , 6. Yellowish sandstone, 7. Amber-bearing levels. C. Outcrop view. 1. Limestone with rudists. 2. Amber bearing levels. 3. Yellow sandstones.

Figure 2. Caractéristiques de l'ambre santonien de Belcodène. A. Grains recueillis dans le sédiment marneux feuilleté à débris de lignite. B-C. Grains jaunes translucides en forme de goutte. D. Grain en forme de goutte à cortex craquelé. E. Grains rougeâtres à cortex craquelé en forme de galette. F. Section en lame mince d'un grain en forme de goutte avec son cortex rouge. G. Section en lame mince d'un grain en forme de goutte avec un cortex rouge prolongé vers le centre par un manchon de filaments. H. Bille d'ambre au MEB montrant le cortex externe à surface craquelée (barre). I. Section en lame mince d'une bille d'ambre opaque.

Figure 2. Characteristics of the Santonian amber from Belcodène. A. Grains collected from the laminated sediment associated with lignitic debris. B-C. Translucent yellow drop-shaped grains. D. Drop-shaped grain with cracked cortex. E. Flattened reddish grains with cracked cortex. F. Thin section of drop-shaped grain with red cortex. $\mathbf{G}$. Thin section of drop-shaped grain with red cortex extended to the center by a ring of filaments. $\boldsymbol{H}$. Drop-shaped amber piece under SEM, showing the extern cortex with cracked surface (bar). I. Thin section of an opaque drop-shaped amber piece.

Figure 3. A-B. Croûte calcitique enveloppant les grains d'ambre (lumière naturelle). C. Grain noduleux opaque. D. Section en lame mince d'un grain noduleux. E. Grains d'ambre 
renfermant à la périphérie une enclave du sédiment marin de dépôt. F. Arthropode indéterminé piégé dans l'ambre.

Figure 3. A-B. Calcite crust enveloping an amber piece. C. Nodular opaque grain. D. Thin section of nodular grain. $\boldsymbol{E}$. Piece of amber containing at the periphery an enclave of marine sediment. F. Undetermined arthropod included in amber.

Figure 4. Actinomycètes de l'ambre de Belcodène. A-B. Actinomycètes de type A se dévelppant à partir de la périphérie (en bas) avec leur terminaison caractéristique en V.C. Actinomycètes de type B en amas isolés. D-I. Filaments à terminaisons spiralées rappelant des hyphes aériens d'actinomycètes de l'espèce Streptomyces coelicolor Muller 1908. J. Actinomycète de type D.

Figure 4. Actinomycetes from Belcodène amber. A-B. Actinomycetes A showing the characteristic V termination. C. Actinomycete B in isolated pellets. D-I. Filaments showing spiral endings like aerial hyphae of Streptomyces coelicolor Muller 1908. J. Actinomycetes D.

Figure 5. Bactéries à gaine (?). A. Mycélium buissonnant se développant à partir de la périphérie vers le centre du grain en haut à droite. B. Filaments ramifiés. C. Filaments ramifiés montrant un aspect spiralé irrégulier. D. Grain d'ambre montrant des buissons de filaments partant de la périphérie (en bas) et pénétrant dans des zones sombres à forte concentration probable en fer et manganèse (flèche). E. Détail de touffe de filaments se chargeant avec un manchon rouge-orange à la proximité des zones de concentration (flèche). F-G. Détail des filaments pouvant présenter un manchon rouge-orange et divers épaississements ou agglomérats. H. Vue en microscopie fluorescente montrant le signal autofluorescent (en jaune-orangé) des filaments et le manchon opaque non fluorescent. I. Vue en microscopie fluorescente en mode réflexion montrant une partie fine centrale cylindrique réfléchissante, en bleu (flèches), et la surface réfléchissante du manchon, également en bleu.

Figure 5. Sheathed bacteria (?). A. Bushy mycelium growing from the periphery to the center of the grain (to right). B. Branched filaments. C. Branched filaments showing a spiralirregular appearance. D. Grain of amber showing bushing filaments penetrating in dark areas with likely high concentration of iron and manganese. $\boldsymbol{E}$. Detail of tuft of filaments with an orange-red coat near areas with high concentration (arrow). F-G. Detail of filaments 
presenting irregularly red-orange coat and various thickenings or lumps. $\boldsymbol{H}$. View in fluorescence microscopy showing autofluorescent signal (yellow-orange) of the filaments and the non fluorescent coat (black). I. Fluorescence microscopy image in reflection mode showing a fine cylindrical reflecting central part (in blue, arrows) and the reflecting surface (also in blue) of the coat.

Figure 6. Autres inclusions filamenteuses. A-B. Bacterium (?) A. Filaments en rubans torsadés se développant à partir de la périphérie formant ici un manchon épais de plusieurs millimètres. B. Filaments à terminaison verticillée donnant un aspect en étoile. C-E. Champignon filamenteux avec conidiophores (cp) et conidies (cd). F. Morphotype indéterminé 1, constitué par un filament allongé supportant un faisceau de filaments rayonnants. G-H. Morphotype indéterminé 2 représenté par des pelotes contigües de fins filaments enchevêtrés évoquant la croissance de certains mycéliums d'actinomycètes.

Figure 6. Other filamentous inclusions. A-B. Bacterium (?) A. Ring of several millimeters thick constituted by ribbon like filaments growing from the periphery. B. Filaments terminated by verticillate structure giving a stellate appearance. $\boldsymbol{C}$-E. Filamentous fungus with conidiophore (cp) and conidia (cd). F. Undetermined morphotype 1, comprising an elongated filament supporting a bundle of radiating filaments. $\boldsymbol{G}-\boldsymbol{H}$. Undetermined Morphotype 2 represented by adjoining pellets of tangled thin filaments reminiscent of some mycelia growth of actinomycetes. 

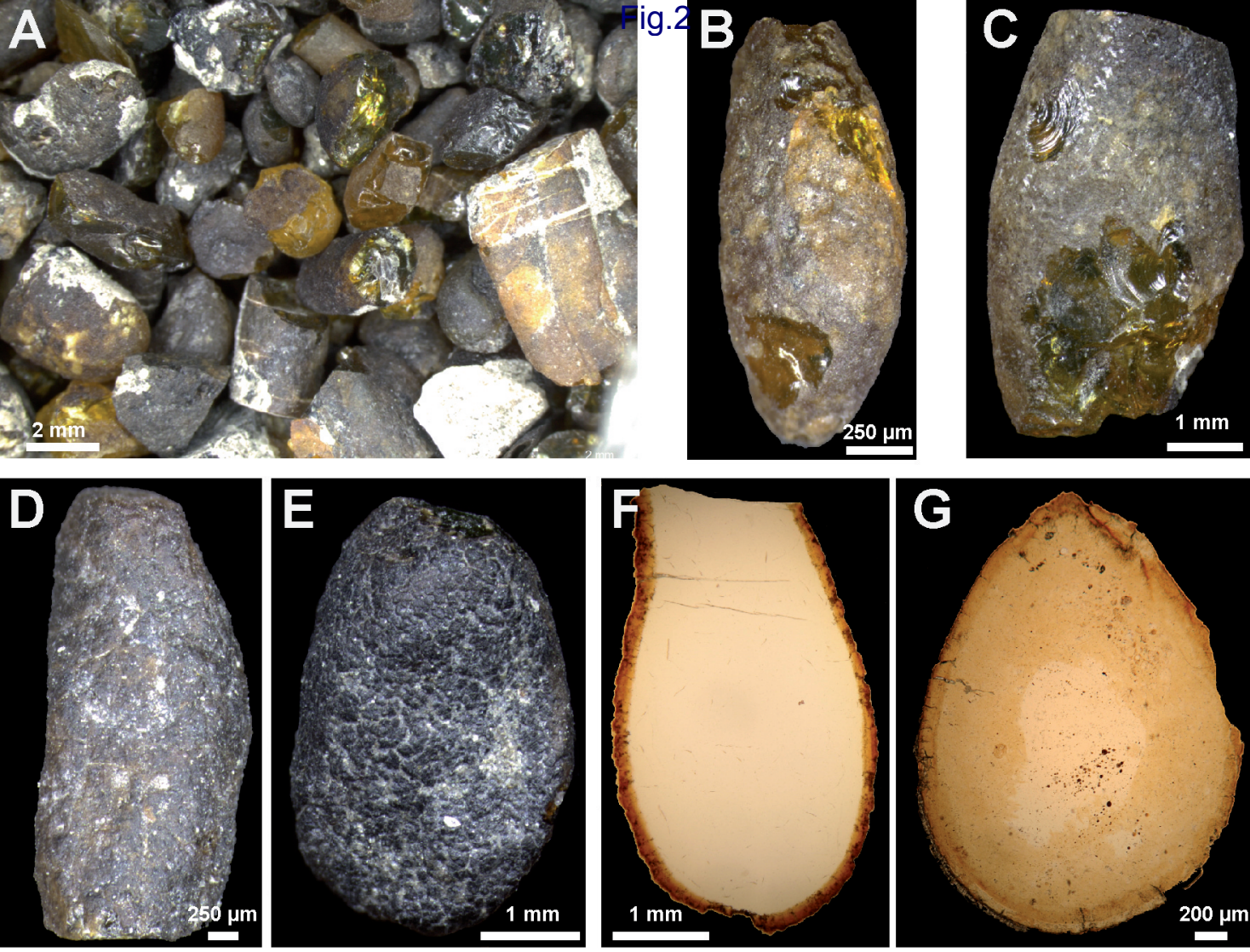

H
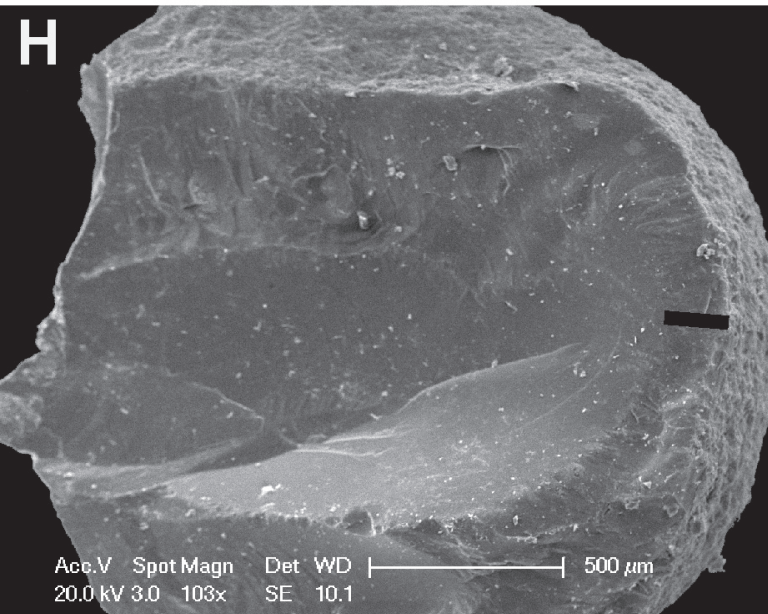

Age.V Spot Mag

Det WD

$20.0 \mathrm{kV} 3.0 \quad 103 \mathrm{x}$ SE 10.1

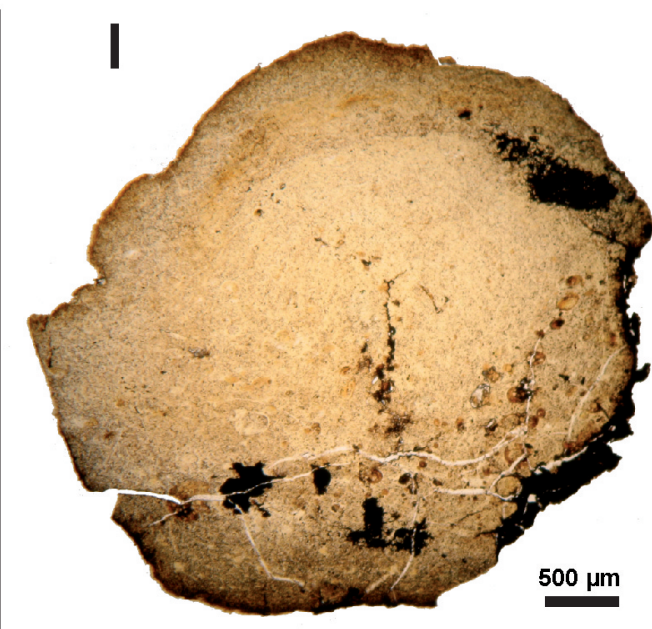


N67?

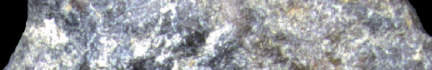

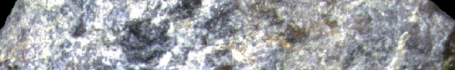

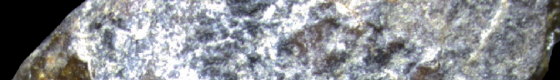
f.

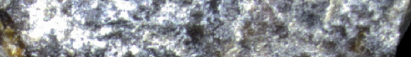
3.t.

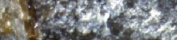
18 QW.

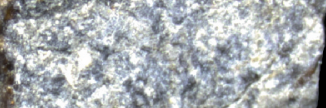

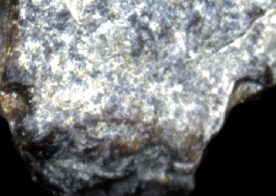

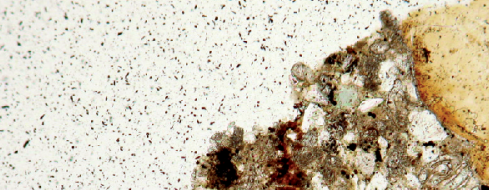

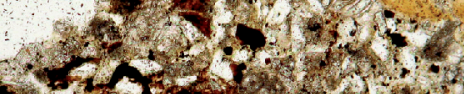

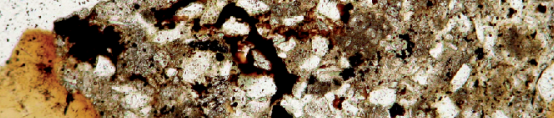

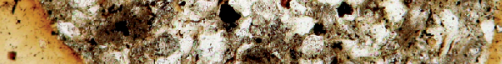

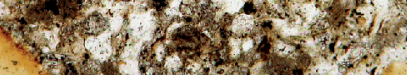

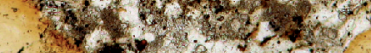

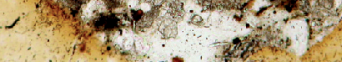
$+3 x^{2}$
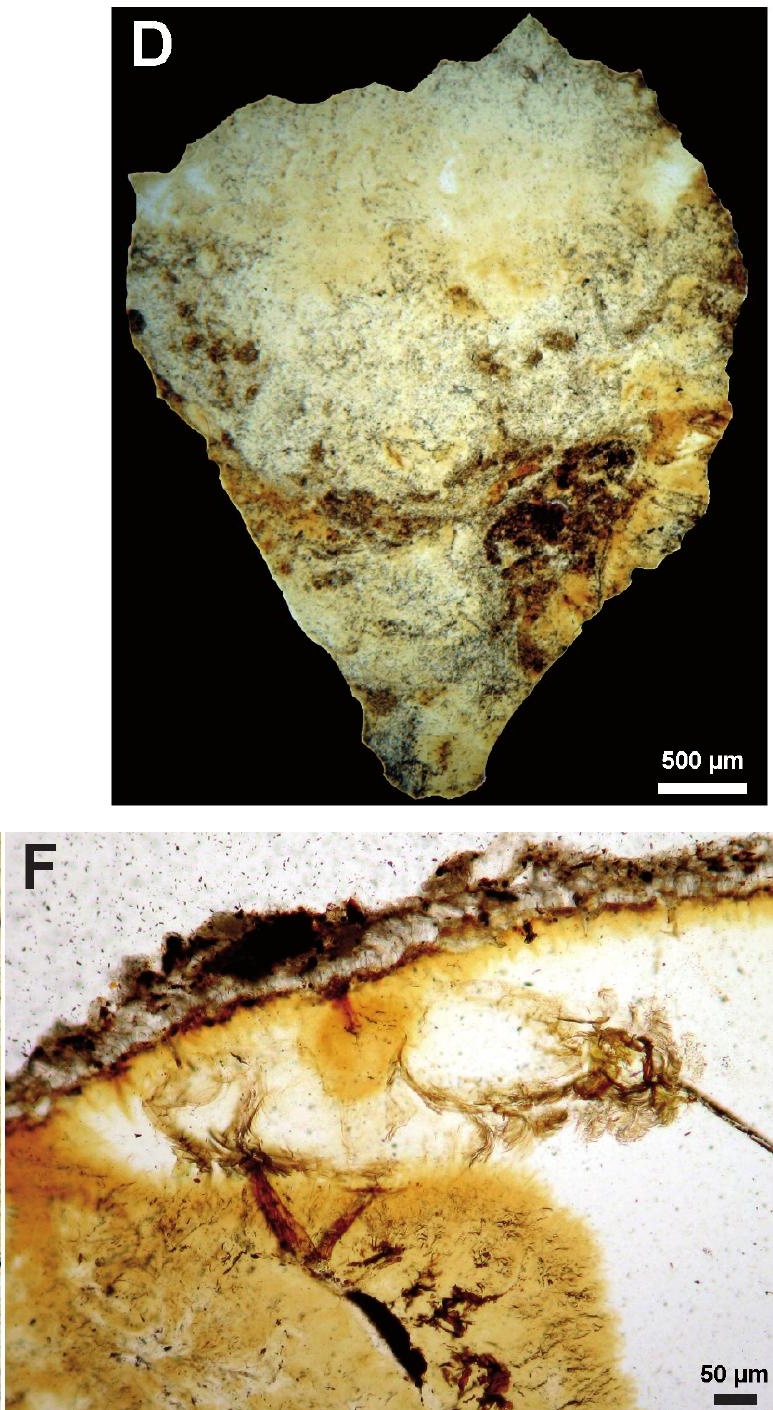
c. a

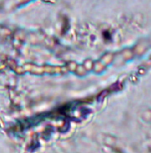

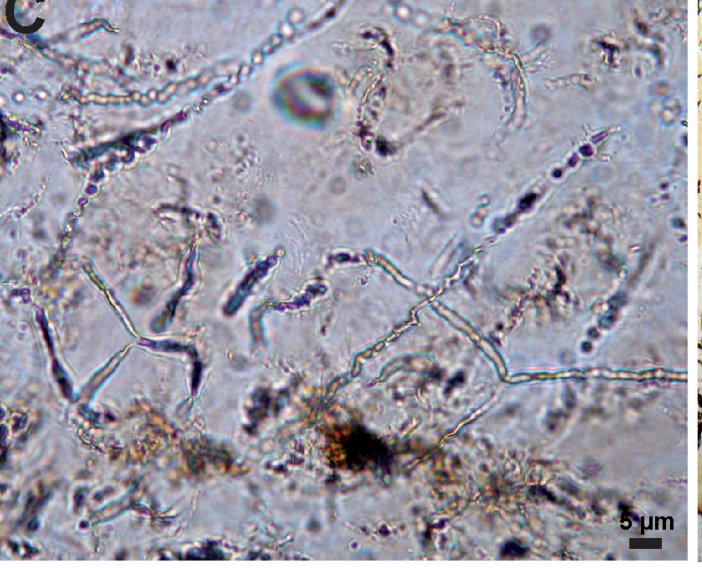

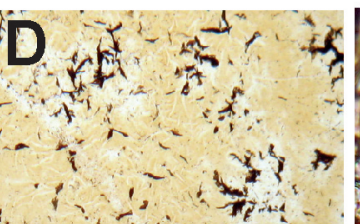

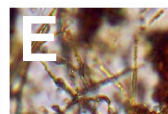
$10 \times 2 \times 3$

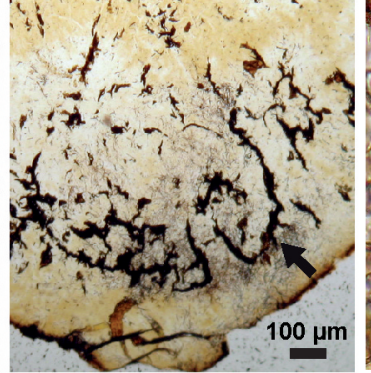
5if

F

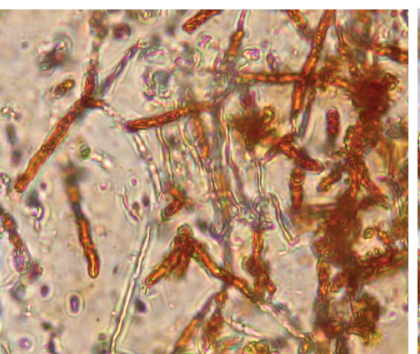

क 1
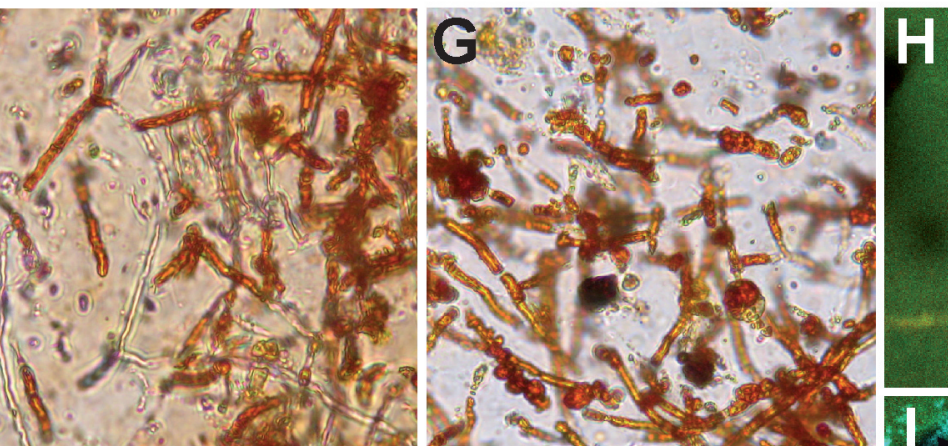

t 17

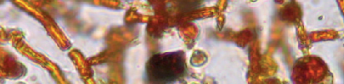

2.

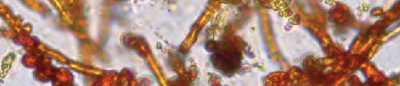

$5 \mu \mathrm{m}$

(1)
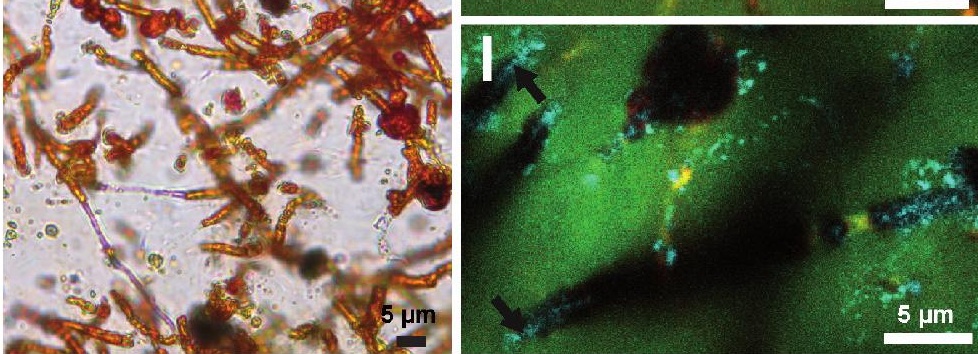
